\title{
Risk factors for sensitisation to methyltetrahydrophthalic anhydride
}

Kozo Yokota, Yasushi Johyama, Kyohei Yamaguchi, Yukio Fujiki, Tatsuya Takeshita, Kanehisa Morimoto

\begin{abstract}
Objectives-To examine an association between specific IgE to methyltetrahydrophthalic anhydride (MTHPA) and exposure time, atopic history, smoking habits, and total IgE concentrations.

Methods-A cross sectional survey was carried out on a population of 148 workers from two condenser plants using epoxy resin with MTHPA, an acid anhydride curing agent known to cause allergy.

Results-Using a Pharmacia CAP system with a MTHPA human serum albumin conjugate, specific IgE antibody was detected in serum from $97(66 \%)$ out of the 148 workers exposed to MTHPA. Stepwise multiple linear regression analysis showed a striking relation between log concentrations of specific and total IgE $(P<0.0001)$. Furthermore, when the workers were divided into two groups according to a cut-off point $(100 \mathrm{IU} / \mathrm{ml})$ between low and high total IgE, current smoking was significantly $(P=0.025)$ associated with specific IgE production only in the group with low total IgE ( $<100 \mathrm{IU} / \mathrm{ml})$.

Conclusions-Smoking is the most significant risk factor for raising specific IgE to MTHPA in the group with low total IgE concentrations.
\end{abstract}

Matsushita Science

Center Of Industrial

Hygiene, 7-6

Tonoshima-cho,

Kadoma, Osaka 571, Japan

K Yokota

Y Johyama

K Yamaguchi

Y Fujiki

Department of

Hygiene and

Preventive Medicine,

Osaka University

School of Medicine,

2-2 Yamada-oka, Suita,

Osaka, 565, Japan

K Yokota

T Takeshita

K Morimoto

Correspondence to: Professor Kanehisa

Morimoto, Department of

Mygiene and Preventive

Medicine, Osaka University

School of Medicine, 2-2

Yamada-oka, Suita, Osaka

565, Japan.

Accepted 10 April 1997
(Occup Environ Med 1997;54:667-670)

Keywords: methyltetrahydrophthalic anhydride; smoking habits; specific IgE production

Acid anhydrides are widely used in the production of alkyd resins and as curing agents for epoxy resins. The major health hazards are mucosal and skin irritation and sensitisation of the respiratory tract. ${ }^{1}$

The risk of sensitisation depends on the relation between smoking status and the degree of exposure to occupational allergens, which include coffee bean dust, ${ }^{2}$ ispaghula, ${ }^{2}$ and tetrachlorophthalic anhydride (TCPA) ${ }^{3}$ However, this relation is controversial for acid anhydrides. ${ }^{3-7}$ Atopy is recognised as a risk factor for allergy to laboratory animals. ${ }^{8}$ These findings focused our interest on the relation between some risk factors (smoking, atopic history, and total IgE) and the increases in specific IgE concentrations.

The purpose of this study was therefore to clarify the risk factors for sensitisation to methyltetrahydrophthalic anhydride (MTHPA).
This approach enables us to offer further protection from allergic disorders.

\section{Subjects and methods}

PLANTS

Two plants (A and B) that were investigated manufacture condensers for electric appliances. MTHPA is used as a hardener in an epoxy resin system for electric insulation and protection. The manufacturing process in each plant consisted of assembly (zone 1), loading and hardening (zone 2), and inspection (zone $3)$. After the condensers are assembled automatically, a small amount of epoxy resin mixture is poured into them. They pass through a curing oven at a temperature of $100^{\circ} \mathrm{C}$. After curing, they are tested electrically. The main exposure originates from the curing ovens. The zones in plant A were separated by a partition and doors to prevent contamination by the MTHPA vapour from the ovens, and only zone 2 in plant B was separated. However, it was found that, particularly in plant $A$, air moved from zone 2 to other zones in the workshop. Plant A started continuous production in 1982 and plant B in 1976. Plant A was investigated in December 1994 and February 1995, and plant B in July 1995.

\section{SUBJECTS}

In plant A, 75 persons worked with MTHPA and $73(97 \%)$ agreed to participate in the survey. In plant $B$, of 103 persons $75(73 \%)$ agreed to take part. They were divided into two types of MTHPA exposure categories-namely, continuous (group C) and intermittent (group I). In total, 30 workers in group $C$ in these plants refused to participate for personal reasons.

Forty five (plant A) and 66 (plant B) subjects in group $C$ had been continuously exposed to MTHPA in different manufacturing processes. In these plants, 37 subjects (group I) had intermittent (once a day, a few times a week, or once a month) short time exposures-they were assistants, repairmen, and technicians. The short exposures lasted for 15-60 minutes a day. Intermittent exposure concentrations have not been measured yet.

Altogether 148 exposed workers were investigated. As control subjects, 25 persons (age 21-54; three women) from other parts of the workshop and offices with little or no exposure to MTHPA were randomly selected in plant A. Informed consent was obtained from the study participants. 
Table 1 Air concentrations of methyltetrahydrophthalic anhydride (MTHPA) in different parts of the workshop in plants $A$ and $B$

\begin{tabular}{|c|c|c|c|c|}
\hline \multirow[b]{2}{*}{ Zone } & \multicolumn{2}{|l|}{ Plant A } & \multicolumn{2}{|l|}{ Plant B } \\
\hline & $\begin{array}{l}\text { Measure- } \\
\text { ments }(n)\end{array}$ & $\begin{array}{l}\text { MTHPA } \\
\left(\mu g / m^{3}\right)\end{array}$ & $\begin{array}{l}\text { Measure- } \\
\text { ments }(n)\end{array}$ & $\underset{\left(\mu g / m^{3}\right)}{M T H P A}$ \\
\hline \multicolumn{5}{|l|}{1} \\
\hline Assembly 1 & 5 & $30.2(7.47-102)$ & 4 & $4.93(1.36-14.9)$ \\
\hline $\begin{array}{l}\text { Assembly } 2 \\
2\end{array}$ & 4 & $63.9(14.3-421)$ & - & - \\
\hline Loading and hardening 1 & 5 & $68.4(31.2-124)$ & 4 & $61.1(23.8-107)$ \\
\hline $\begin{array}{l}\text { Loading and hardening } 2 \\
3\end{array}$ & 4 & $65.9(15.6-278)$ & 4 & $56.8 \quad(21.7-149)$ \\
\hline Inspection & 4 & $25.5(12.9-67.9)$ & 4 & $5.49(0.68-22.4)$ \\
\hline
\end{tabular}

Values are expressed as geometric mean and range.

\section{MEDICAL EXAMINATION}

The subjects completed a questionnaire about their symptoms (from the eyes, nose, pharynx and lower respiratory tract), smoking habits, and occupational history. A subject was defined as atopic when he had a history of pollenosis, asthma, atopic eczema, or urticaria during childhood or adolescence. Occupational asthma was defined as attacks of wheezing breath, dyspnoea, and cough, recovering either at weekends or on holiday, and starting after first exposure to MTHPA. Ocular and nasal symptoms were defined similarly. The subjects were classified as current or former smokers or non-smokers. A physician (KY) interviewed the subjects and took a brief history, directed at the symptoms and their relation to work, without knowledge of the symptoms and smoking and occupational histories already recorded in the questionnaire. After an interview, venous blood samples were collected for serological investigations.

\section{AIR SAMPLING AND ANALYSIS}

Concentrations of MTHPA in air have been measured in the two plants every six months from 1993 to 1995. Concentrations of MTHPA were determined by area sampling on silica gel tubes. The sampling rate was $1 \mathrm{l} / \mathrm{min}$ and the sampling time $60-120$ minutes. The anhydride analysis followed, with slight modifications, the procedure of Pfäffli et al. ${ }^{9}$ The detection limit was $1.0 \mu \mathrm{g} / \mathrm{m}^{3}$ in a 201 air sample.

\section{ANTIBODY DETERMINATIONS}

Pharmacia (Pharmacia Diagnostics AB, Uppsala, Sweden) provided immunocaps made from hydrophilic polymer, to which an MTHPA human serum albumin conjugate was fixed. Specific IgE antibody to MTHPA was measured by means of a Pharmacia CAP system. The results were expressed as $\mathrm{U} / \mathrm{ml}$ and the detection limit was $0.35 \mathrm{U} / \mathrm{ml}$. Total IgE concentrations were also measured by means of the CAP system according to the manufacturer's instructions.

\section{STATISTICAL TESTS}

Total and specific IgE concentrations were evaluated as $\log$ values. Differences were tested by unpaired Student's $t$ test, $\chi^{2}$ test, and Fisher's exact test.

Multiple linear regression analysis was performed to evaluate some risk factors for sensitisation. The subjects were divided into two groups according to a geometric mean total IgE of $100 \mathrm{IU} / \mathrm{ml}$ in the whole population sample. Log concentrations of specific IgE were used as a dependent variable, and plant, sex, age, exposure style, exposure time, atopic history, current smoking, and log total IgE were used as independent variables. In particular, the predictors of log concentrations of specific IgE were isolated by stepwise multiple linear regression analysis. These analyses were conducted with the SPSS computer program. ${ }^{10}$ A $P$ value $\leqslant 0.05$ was regarded as significant.

\section{Results}

Table 1 shows the results for the air samples obtained in the various work zones in the two plants. The MTHPA concentrations in plant A were significantly $(P<0.05)$ higher than those in plant B in assembly lines. A similar but nonsignificant tendency was found for the MTHPA concentrations in inspecting lines. By contrast, there was no difference in the MTHPA concentrations in loading and hardening processes between these plants.

Table 2 shows characteristics of the population by type of MTHPA exposure in plants $A$ and $\mathrm{B}$. Comparisons were performed between the groups within each plant. The sex distribution was significantly $(P<0.001)$ different in plant $\mathrm{A}$ because more than half of the workers in the assembly and inspecting lines were women. A similar but non-significant tendency was found for the sex distribution in plant $B$. In plant A, group $C$ had been exposed for a shorter time than group I $(\mathrm{P}<0.05)$, and included a smaller proportion of smokers than did group I $(P<0.02)$. There were no significant differences between the groups in each plant for total IgE concentration. No sig-

Table 2 Profiles of workers in the various MTHPA exposure groups in plants $A$ and $B$

\begin{tabular}{|c|c|c|c|c|}
\hline & \multicolumn{2}{|l|}{ Plant $A$} & \multicolumn{2}{|l|}{ Plant $B \ddagger$} \\
\hline & Continuous (C) $n=45$ & Intermittent (I) $n=28$ & Continuous (C) $n=66$ & Intermittent (I) $n=9$ \\
\hline $\begin{array}{l}\text { F/M (n) } \\
\text { Age (y, mean (range)) } \\
\text { Exposure time (y, mean (range)) } \\
\text { Current smokers (n (\%)) } \\
\text { Atopic history (n (\%)) } \\
\text { Total IgE (IU/ml, geometric mean (range)) } \\
\text { Positive specific IgE (n (\%)) } \\
\text { Specific IgE concentration in subjects with positive } \\
\text { specific IgE (U/ml, geometric mean (range)) }\end{array}$ & $\begin{array}{cl}28 / 17^{\star \star \star} \\
34.5 & (19-53) \\
5.2 & (0.2-13)^{\star} \\
5 & (11.1) \dagger \\
6 & (13.3) \\
59.6 & (5.13-1290) \\
26 & (57.7) \\
8.1 & (0.58-106)\end{array}$ & $\begin{aligned} 5 / 23 & \\
35.0 & (19-58) \\
7.4 & (0.5-19) \\
11 & (39.3) \\
7 & (25.0) \\
102 & (6.15-895) \\
20 & (71.4) \\
7.6 & (0.50-105)\end{aligned}$ & $\begin{aligned} 24 / 42 & \\
37.1 & (19-56) \\
12.5 & (1.3-20) \\
35 & (53.0) \\
24 & (36.4) \\
124 & (3.02-4786) \\
45 & (68.2) \\
8.4 & (0.36-174)\end{aligned}$ & $\begin{array}{cl}0 / 9 & \\
35.3 & (25-56) \\
10.4 & (3.3-20) \\
4 & (44.4) \\
2 & (22.2) \\
95.7 & (15.5-1002) \\
6 & (66.6) \\
4.5 & (0.36-31.5)\end{array}$ \\
\hline
\end{tabular}

${ }^{\star} \mathrm{P}<0.05 ;+\mathrm{P}<0.02 ;{ }^{\star \star \star} \mathrm{P}<0.001 ; v$ group $\mathrm{I}$ in plant $\mathrm{A}$.

Comparisons were performed between the groups within each plant.

$\ddagger$ Values of $>0.35 \mathrm{U} / \mathrm{ml}$ were considered positive. 
Table 3 Work related symptoms in sensitised (positive specific IgE) and unsensitised subjects among 148 workers with present exposure to MTHPA

\begin{tabular}{|c|c|c|c|c|c|c|}
\hline & \multicolumn{3}{|l|}{ Plant $A$} & \multicolumn{3}{|l|}{ Plant B } \\
\hline & Sensitised $n=46$ & $\begin{array}{l}\text { Unsensitised } \\
n=27\end{array}$ & $P$ value & Sensitised $n=51$ & $\begin{array}{l}\text { Unsensitised } \\
n=24\end{array}$ & $P$ value \\
\hline \multicolumn{7}{|c|}{ Work related symptoms (n (\%)): } \\
\hline Eyes & $28(60.9)$ & $6(22.2)$ & $<0.002$ & $17(33.3)^{\star \star}$ & $2(8.3)$ & $<0.03$ \\
\hline Nose & $40(87.0)$ & $5(18.5)$ & $<0.0001$ & $25(49.0) \ddagger$ & $4(16.7)$ & $<0.02$ \\
\hline Sneezing & $36(78.3)$ & $4(14.8)$ & $<0.0001$ & $23(45.1)^{\star \star \star}$ & $3(12.5)$ & $<0.01$ \\
\hline Secretion & $39(84.8)$ & $3(11.1)$ & $<0.0001$ & $24(47.1) t$ & $4(16.6)$ & $<0.02$ \\
\hline Blockage & $20(43.5)$ & $3(11.1)$ & $<0.005$ & $6(31.3)$ & 0 & $<0.002$ \\
\hline Pharynx & $4(8.7)$ & $2(7.4)$ & NS & $0^{\star}$ & 0 & NS \\
\hline Cough & $8(17.4)$ & $1(3.7)$ & NS & $5(9.8)$ & 0 & NS \\
\hline Asthma & 0 & 0 & NS & 0 & 0 & NS \\
\hline
\end{tabular}

${ }^{\star} \mathrm{P}<0.05 ;{ }^{\star \star} \mathrm{P}<0.01 ;{ }^{\star \star \star} \mathrm{P}<0.001 ;+\mathrm{P}<0.0005 ; \ddagger \mathrm{P}<0.0001 v$ sensitised in plant $\mathrm{A}$.

nificant differences were found in the frequency or the concentration of positive specific IgE antibody between the groups in each plant. All the specific IgE values for the 25 controls were $<0.35 \mathrm{U} / \mathrm{ml}$.

For work related symptoms, sensitised workers in each plant who had present exposure had significantly more complaints from the eyes and nose than unsensitised workers (table 3 ; $P<0.03)$. The sensitised workers in plant $A$ had higher frequencies for eyes, nose, and pharynx than those in plant $B(P<0.05)$. Ocular and nasal symptoms were associated with specific IgE to MTHPA. None of the subjects had yet had symptoms of work related asthma.

Tables 4 and 5 show the results of multiple linear regression analysis for predictors of log concentrations of specific IgE. Four variables were included in the equation as factors with significance (table 5). In the group with low total IgE concentrations ( $<100 \mathrm{IU} / \mathrm{ml}$ ), age, current smoking, and $\log$ total IgE showed a relation with $\log$ specific IgE concentrations. In the group with high total IgE concentrations $(\geqslant 100 \mathrm{IU} / \mathrm{ml}$ ), sex and log total IgE showed a relation with log specific IgE concentrations.

\section{Discussion}

In the two plants studied, the frequency of occurrence of positive specific IgE in workers currently exposed to MTHPA was 97 of 148 $(66 \%)$, much higher than that ( $7 \%$ to $44 \%)$ found in previous studies of workers exposed to MTHPA, ${ }^{41}$ hexahydrophthalic anhydride (HHPA), ${ }^{5}{ }^{12}$ phthalic anhydride, ${ }^{6}$ TCPA, $^{37}$ or trimellitic anhydride. ${ }^{13}$ The participation rate in workers with current exposure in plants A and $B$ was $97 \%$ and $75 \%$ respectively. Thus, it is unlikely that the high frequency is due to selection bias. Airborne MTHPA concentrations were fairly low during the period between 1993 and 1995 (table 1). The frequency of positive specific IgE in this study is much higher than that in our previous study ${ }^{11}(64 \%$ and $24 \%$ ) in workers exposed continuously to MTHPA, because the exposure intensity was much lower in the second group (0.86-15.0 $\left.\mu \mathrm{g} / \mathrm{m}^{3}\right)$. Because of the high frequency of positive specific $\operatorname{IgE}$, it is possible that airborne MTHPA concentrations were higher before 1993, and that the high frequency we found mainly reflects previous exposures.

Groups $C$ and I in each plant did not differ in the frequency or the concentration of positive specific IgE (table 2). This finding suggests that intermittent short time exposures may have an effect on the production of specific IgE antibodies, and is consistent with the results of a study in a factory using HHPA. ${ }^{5}$ Our interest should therefore be focused on exposure levels of intermittently exposed workers (group I). However, intermittent exposures have not yet been measured.

Work related ocular and nasal symptoms were significantly associated with MTHPA specific IgE (table 3 ). This indicates that there is an IgE mediated mechanism in most cases of work related symptoms associated with MTHPA exposure. When 26 (plant A) and 45 sensitised workers (plant B) in group C were compared, those in plant $\mathrm{A}$ had higher frequencies for all eye and nose symptoms ( $P<0.03$, data not shown). This reflects the difference in the MTHPA concentrations between the two plants.

Nielsen et $a l^{14}$ reported that asthma was found in $10 \%$ of workers with high exposure to MTHPA (time weighted average $20-150 \mu \mathrm{g} /$

Table 4 Multiple linear regression results for predictor variables of log concentrations of specific IgE in 148 factory workers by total IgE concentration

\begin{tabular}{|c|c|c|c|c|c|c|c|c|c|}
\hline & \multicolumn{3}{|c|}{ Total $\operatorname{IgE}<100(n=76)$} & \multicolumn{3}{|c|}{ Total $I g E \geqslant 100(n=72)$} & \multicolumn{3}{|c|}{ Total $(n=148)$} \\
\hline & $B$ & $S E M$ & Pvalue & $B$ & $S E M$ & Pvalue & $B$ & $S E M$ & Pvalue \\
\hline Plant & 0.0001 & 0.1567 & 0.99 & -0.0688 & 0.3140 & 0.83 & 0.0071 & 0.1627 & 0.97 \\
\hline Sexf & 0.0855 & 0.1687 & 0.61 & -0.6254 & 0.2706 & $0.024^{\star}$ & -0.2373 & 0.1557 & 0.13 \\
\hline Age (y) & 0.0222 & 0.0079 & $0.0066^{\star}$ & 0.0240 & 0.0148 & 0.11 & 0.0207 & 0.0080 & $0.010^{\star}$ \\
\hline Atopic history & -0.0538 & 0.1539 & 0.73 & -0.2519 & 0.2324 & 0.28 & -0.1643 & 0.1402 & 0.24 \\
\hline Current smoking & 0.2471 & 0.1649 & 0.14 & -0.0195 & 0.2520 & 0.94 & 0.1579 & 0.1496 & 0.29 \\
\hline Exposure style $\star \star$ & -0.0356 & 0.1681 & 0.83 & -0.0416 & 0.2795 & 0.88 & -0.0575 & 0.1582 & 0.72 \\
\hline Exposure time (y) & -0.0224 & 0.0148 & 0.13 & -0.0169 & 0.0291 & 0.57 & -0.0170 & 0.0152 & 0.27 \\
\hline Log total IgE & 0.7062 & 0.1691 & $0.0001^{\star}$ & 0.7967 & 0.3013 & $0.010^{\star}$ & 0.7331 & 0.1012 & $<0.0001^{\star}$ \\
\hline
\end{tabular}

$\star$ Denotes significant values; + plant $A=1$, plant $B=0$; $\ddagger$ male $=1$, female $=0$; $\uparrow$ presence of atopic history $=1$, absence of it $=0$; If current smoking $=1$, ex and never $=0 ; \star \star$ continuous $=1$, intermittent $=0 ; B=$ regression coefficient; $S E M=$ standard error of the mean. 
Table 5 Independent variables selected by multiple linear regression analysis in 148 factory workers by total IgE concentration (stepwise method, Pin=00.05, Pout $=00.10$ )

\begin{tabular}{|c|c|c|c|c|c|c|c|c|c|c|c|c|}
\hline & \multicolumn{4}{|c|}{ Total $\operatorname{IgE}<100(n=76)$} & \multicolumn{4}{|c|}{ Total $I g E \geqslant 100(n=72)$} & \multicolumn{4}{|c|}{ Total $(n=148)$} \\
\hline & $B$ & SEM & Beta & P value & $B$ & $S E M$ & Beta & Pvalue & $B$ & $S E M$ & Beta & Pvalue \\
\hline Intercept & -1.531 & & & & -0.735 & & & & -1.381 & & & \\
\hline \multicolumn{13}{|c|}{ Independent variables included in the model $(P<0.05)$ : } \\
\hline Sex & & & & & -0.452 & 0.221 & -0.232 & 0.045 & & & & \\
\hline Age (y) & 0.015 & 0.006 & 0.246 & 0.016 & & & & & 0.013 & 0.006 & 0.163 & 0.022 \\
\hline Current smoking & 0.294 & 0.129 & 0.227 & 0.025 & & & & & & & & \\
\hline Log total IgE & 0.666 & 0.164 & 0.400 & 0.0001 & 0.735 & 0.287 & 0.291 & 0.013 & 0.677 & 0.097 & 0.491 & $<0.0001$ \\
\hline
\end{tabular}

Beta=standardised regression coefficient.

$\mathrm{m}^{3}$ ). In the present study, however, no subject had yet developed symptoms of work related asthma. The low exposure concentrations in recent years may explain this. Alternatively, this may be due to selection bias in the study subjects, as sensitised subjects who became seriously symptomatic should have left the workshop. To consider this question, further prospective studies among sensitised subjects need to be done.

As shown in table 4, age and sex were significantly associated with $\log$ specific IgE concentrations while controlling for exposure time, exposure style, and other independent variables. Age is a confounder to exposure time $(r=0.63, \mathrm{P}<0.001)$. Because age at starting to work with MTHPA displayed no correlation with exposure time ( $r=0.064, \mathrm{P}=0.22)$, it was used as an independent variable instead of age. However, the new variable still significantly $(\mathrm{P}<0.01)$ contributed to $\log$ specific IgE. Thus age is likely to be a predictor of log specific IgE concentrations in this cross sectional survey of a Japanese occupational population. On the other hand, sex cannot be concluded to be a predictor, as it was marginally significant $(\mathrm{P}=0.045)$ in the group with high total IgE.

As shown in table 5, log total IgE was the most significant predictor of log specific IgE concentrations $(\mathrm{P}<0.0001)$. This result suggests that total IgE concentration in a subject may represent his or her potential for immunological responses. However, it is possible that total IgE concentrations may be explained by sensitisation to MTHPA. Further prospective studies, in which total IgE concentrations in persons are determined before assignment to the manufacturing processes, are therefore needed to confirm the causal relation of total IgE concentrations with sensitisation to MTHPA.

There are conflicting reports on the effect of current smoking on the increase of specific IgE antibodies in workers exposed to acid anhydride..$^{3-7}$ In a survey of workers exposed to TCPA, ${ }^{3}$ the prevalence ratio for anti-TCPA IgE was 5.8 for smoking and 1.9 for atopy. The most important result of this survey was a significant association of current smoking with log specific IgE concentrations. This finding is consistent with the result from a TCPA factory, ${ }^{3}$ and suggests that smoking predisposed to the development of specific IgE. Interestingly, this correlation was found only in the group with low total IgE (table 5;
$P=0.025)$. No significant difference was found between the groups with high and low total IgE concentrations with regard to the smoking rate ( $40 \%$ and $34 \%$ respectively). These results suggest that a high total IgE concentration may make an independent contribution to the determination of specific $\operatorname{IgE}$ irrespective of smoking status.

As mentioned, smoking may be a preventable risk factor for increasing specific IgE. Based on findings in the present and previous studies, ${ }^{23}$ we advise the cessation of smoking to minimise the risk of specific IgE production with control of exposure to MTHPA.

This work was supported in part by a grant in aid for scientific research from the Ministry of Education, Science, Sports, and Culture of Japan. We thank T Shirakawa (Osler Chest Unit, Churchill Hospital, University of Oxford) for his encourageChurchill

1 Venables KM. Low molecular weight chemicals, hypersensitivity, and direct toxicity: the acid anhydrides. $\mathrm{Br} \mathcal{F}$ Ind Med $1989 ; 46: 222-32$.

2 Zetterström O, Osterman K, Machado O, Johansson SGO. Another smoking hazard: raised serum IgE concentration and increased risk of occupational allergy. $B M F 1981 ; 283$ : 1215-7.

3 Venables $\mathrm{KM}$, Topping $\mathrm{MD}$, Howe $\mathrm{W}$, Luczynska CM, Hawkins R, Taylor AJ. Interaction of smoking and atopy in producing specific IgE antibody against a hapten protein producing specific IgE antibody
conjugate. $B M \Im$ 1985;290:201-4.

4 Welinder H, Nielsen J, Gustavsson C, Bensryd I, Skerfving S. Specific antibodies to methyltetrahydrophthalic anhydride in exposed workers. Clin Exp Allergy 1990;20:63945.

5 Welinder HE, Jönsson BAG, Nielsen JE, Ottosson HE, Gustavsson CA. Exposure-response relationships in the formation of specific antibodies to hexahydrophthalic anhydride in exposed workers. Scand $\mathcal{F}$ Work Environ Health 1994;20:459-65.

6 Nielsen J, Welinder H, Schütz A, Skerfving S. Specific serum antibodies against phthalic anhydride in occupationally exposed subjects. F Allergy Clin Immunol 1988;82:12633.

7 Liss GM, Bernstein D, Genesove L, Roos JO, Lim J. Assessment of risk factors for IgE-mediated sensitization to tetrament of risk factors for IgE-mediated sensitization to tetra-
chlorophthalic anhydride. $f$ Allergy Clin Immunol 1993;92: chloroph

8 Botham PA, Davies GE, Teasdale EL. Allergy to laboratory animals: a prospective study of its incidence and of the influence of atopy on its development. $\mathrm{Br} F$ Ind Med 1987; 44:627-32.

9 Pfaffli P, Savolainen H, Keskinen H. Determination of carboxylic acids in biological samples as their trichloroethylesters by gas chromatography. Chromatographia 1989;27: 483-8.

10 SPSS. SPSSX user's guide. Chicago: SPSS, 1986.

11 Yokota K, Johyama Y, Yamaguchi K, Fujiki Y, Takeshita T, Morimoto $\mathrm{K}$. Study on allergic rhinitis in workers exposed to methyltetrahydrophthalic anhydride. Environ Health Prev Med 1996;1:133-5.

12 Moller DR, Gallagher JS, Bernstein DI, Wilcox TH, Burroughs HE, Bernstein IH. Detection of IgE-mediated respiratory sensitization in workers exposed to hexahydrophthalic anhydride. f Allergy Clin Immunol 1985;75: 663-72.

13 Grammer LC, Harris KE, Sonenthal KR, Ley C, Roach DE. A cross-sectional survey of 46 employees exposed to DE. A cross-sectional survey of 46 employees exp
trimellitic anhydride. Allergy Proc 1992;3:139-42.

14 Nielsen J, Welinder H, Horstmann V, Skerfving S. Allergy to methyltetrahydrophthalic anhydride in epoxy resin workers. Br F Ind Med 1992;49:769-75. 